\title{
Effect of Process Control Agents on the FeSiB Powder Amorphisation by Wet Mechanical Alloying
}

\author{
Bogdan Viorel NEAMTUU ${ }^{1, a}$, Traian Florin MARINCA ${ }^{1, b}$, \\ Horea Florin $\mathrm{CHICINAŞ}{ }^{1, \mathrm{c}}$, lonel CHICINAŞ ${ }^{1, \mathrm{~d}}$, Olivier ISNARD ${ }^{2, \mathrm{e}}$ \\ ${ }^{1}$ Materials Science and Engineering Department, Technical University of Cluj-Napoca, 103-105 \\ Muncii Blv., 400641 Cluj-Napoca, Romania \\ ${ }^{2}$ Institut Néel, CNRS/University Joseph Fourier, BP 166, 38042 Grenoble Cédex 9, France \\ abogdan.neamtu@stm.utcluj.ro*, btraian.marinca@stm.utcluj.ro, chorea.chicinas@stm.utcluj.ro \\ ionel.chicinas@stm.utcluj.ro eolivier.isnard@neel.cnrs.fr
}

Keywords: soft magnetic materials, amorphous powder, wet mechanical alloying, process control agent

\begin{abstract}
Result of research concerning the influence of milling conditions on the amorphisation of the $\mathrm{Fe}_{75} \mathrm{Si}_{20} \mathrm{~B}_{5}$ (at.\%) alloy is presented. Amorphous powder of $\mathrm{Fe}_{75} \mathrm{Si}_{20} \mathrm{~B}_{5}$ (at.\%) was prepared by dry and wet mechanical alloying (MA) route starting from a mixture of $\mathrm{Fe}$, Si and B elemental powders. The mixture was wet/dry milled up to 50 hours. Benzene, oleic acid and ethanol were used as process control agents (PCA) in order to investigate the influence of their chemical composition on the powder amorphisation. The evolution of the powder crystalline structure, thermal stability and magnetic properties were investigated by X-ray diffraction (XRD), differential scanning calorimetry (DSC), thermogravimetry (TG) as well as magnetic measurements versus temperature and field. It is proved that the chemical composition of the PCA (especially the carbon content) plays an important role in the amorphisation process induced by wet MA.
\end{abstract}

\section{Introduction}

Since 1967, when the first ferromagnetic amorphous alloy (Fe80P13C7) was developed [1], the amorphous soft magnetic materials are extensively studied from both, fundamental and applications, point of views due to their excellent soft magnetic properties.

Amorphous soft magnetic materials have been produced by a series of techniques as follow: melt spinning, gas atomisation, mechanical alloying/milling, copper mould casting, vapour deposition, plasma processing etc. Among these techniques, MA has started to be increasingly used to produce amorphous powder. In MA technique, a mixture of elemental powders or pre-alloyed powders is subjected to high energy ball milling process. During this process sandwich like structures are created as results of repeated cold welding and fracturing processes. Also, a large number of defects are induced by milling and a slight increase of the temperature. This will favour the atomic interdiffusion to take place, and finally the alloy is formed [2]. In some cases, together with the milling bodies and powders to be milled, a certain quantity (usually not larger than $5 \mathrm{wt} \%$ of total processed mass powder) of PCA is added [2]. The PCA acts as surfactants reducing the number of cold welding processes leading to the achievement of a balance between cold welding and fracturing phenomena. One of the main drawbacks of this technique is the contamination of the processed powder with atoms resulted from the surfactant decomposition during milling [3].

In this paper, we present the influence of various PCA on the amorphisation of the $\mathrm{Fe}_{75} \mathrm{Si}_{20} \mathrm{~B}_{5}$ (at.\%) alloy. 


\section{Experimental}

The amorphous powder alloy of $\mathrm{Fe}_{75} \mathrm{Si}_{20} \mathrm{~B}_{5}$ was obtained by mechanical alloying starting from a mixture of elemental iron powder - NC 100.24 - (Höganäs), silicon powder 99.9\% (Alfa Aesar) and boron amorphous powder $99.9 \%$ (Alfa Aesar). This mixture will be further referred to as starting sample (ss). The mixture was wet/dry milled up to 50 hours in a planetary ball mill (Pulverisette 6 , Fritsch) under argon atmosphere. For all the samples prepared and presented in this study the milling conditions used for their preparation were identical. High purity benzene $\left(\mathrm{C}_{6} \mathrm{H}_{6}\right)$, oleic acid $\left(\mathrm{C}_{18} \mathrm{H}_{34} \mathrm{O}_{2}\right)$ and ethanol $\left(\mathrm{C}_{2} \mathrm{H}_{5} \mathrm{OH}\right)$ were used in wet milling experiments as PCA.

The structural investigations were made by X-ray diffractions (XRD) using Co radiation (angular range $30-110^{\circ}$ ) and $\mathrm{Cu}$ radiation (angular range $30-80^{\circ}$ ).

The thermal stability of the as milled samples was investigated by differential scanning calorimetry (DSC). All DSC measurements were performed in Ar atmosphere with a heating/cooling rate of $20{ }^{\circ} \mathrm{C} / \mathrm{min}$. The thermogravimetric measurements (TG) were performed in $\mathrm{H}_{2}$ atmosphere with a heating/cooling rate of $20^{\circ} \mathrm{C} / \mathrm{min}$.

The $\mathrm{M}(\mathrm{T})$ curve was recorded on a homemade apparatus using a heating rate of $20{ }^{\circ} \mathrm{C} / \mathrm{min}$. In order to avoid powder oxidation, the powder was sealed in vacuum in a quartz tube.

The magnetization curves, $\mathrm{M}(\mathrm{H})$, were recorded at room temperature using the extraction sample method in a continuous magnetic field of up to $10 \mathrm{~T}$. The saturation magnetizations have been derived from the magnetization curves for a magnetic field higher than $5 \mathrm{~T}$.

\section{Results and discussions}

The XRD patterns of the dry mechanical alloyed powders are presented in figure 1 and compared to that of the wet mechanical alloyed powders using ethanol, oleic acid, and benzene as surfactant.
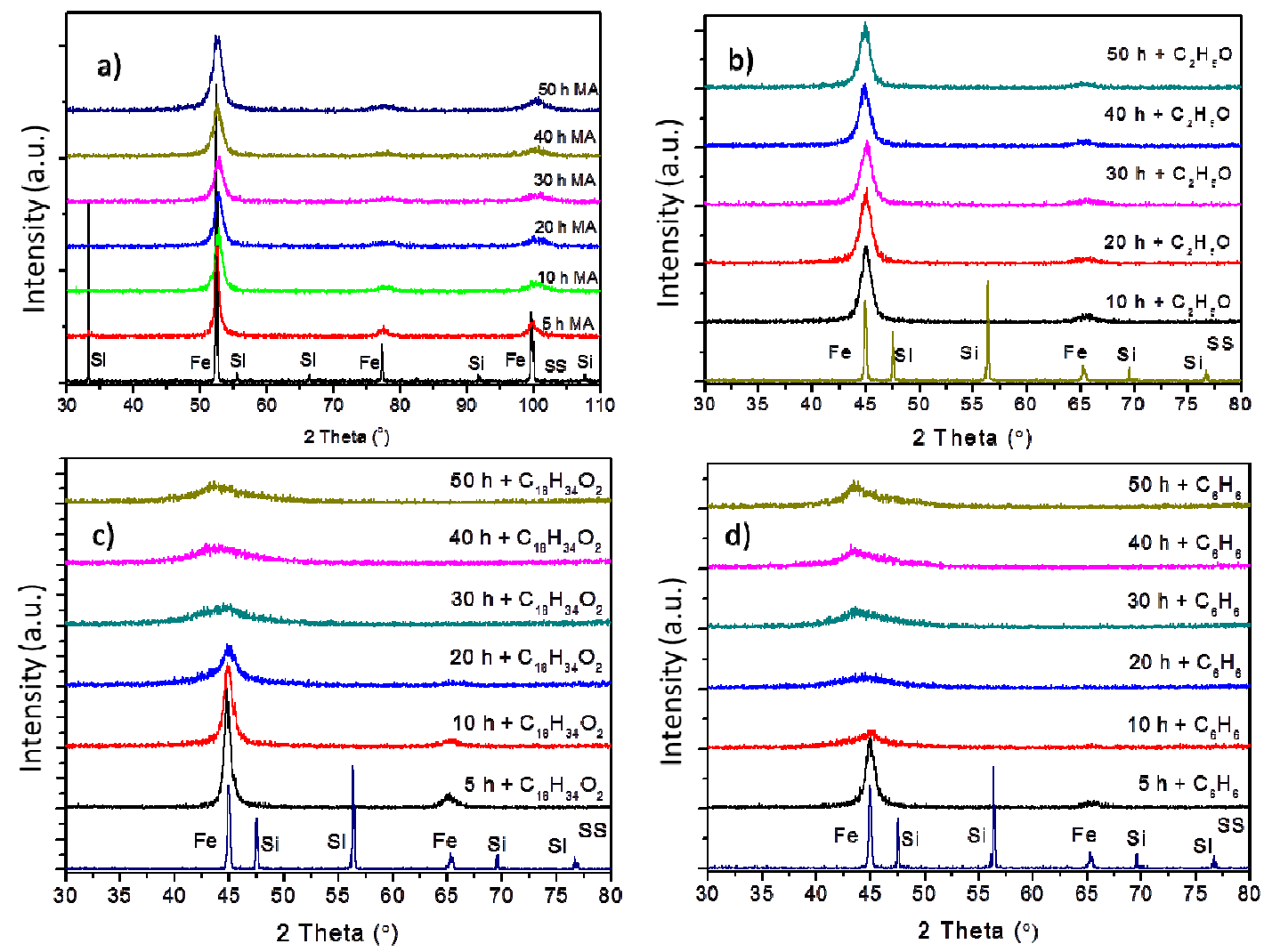

Fig. 1. XRD patterns of the dry mechanical alloyed powders (a) and wet mechanical alloyed powder using ethanol (b), oleic acid (c) and benzene (d) as surfactant. Fig 1a) has been recorded with $\mathrm{Co}-\mathrm{K} \alpha$ radiation and Fig b) to d) with $\mathrm{Cu}-\mathrm{K} \alpha$ 
The evolution of the alloy crystalline structure versus milling time reveals that dry milling and wet milling using ethanol as PCA (Fig. 1.a and b) do not lead to alloy amorphisation. It can be observed that for 5 hours of dry milling the formation of a $\mathrm{Fe}(\mathrm{Si}, \mathrm{B})$ solid solution is obtained. Also, the most intense Bragg reflection of Si (at about 2 theta $=33.2^{\circ}$ ) is noticed prooving that part of $\mathrm{Si}$ did not yet react with Fe or B. After 10 hours of dry or wet milling, within the experimental error limit, the whole of Si and B quantity were dissolved in the Fe structure. After this milling duration, the formation of a nanocrystalline solid solution of $\mathrm{Fe}(\mathrm{Si}, \mathrm{B})$ is evidenced. In the case of dry milled and wet milled powders using ethanol as PCA no further evolution of the XRD spectra can be noticed indicating that, in these specific conditions, the alloy amorphisation cannot be achieved even for long milling of up to 50hours.

In the case of the powder wet milled with oleic acid as PCA, increasing the milling time leads to broadening of the main Bragg reflection. The diffraction pattern of the sample wet milled for 30 hours presents a single and very broad maximum. This may indicate the full amorphisation of the alloy. However, a closer analysis of the peak shape reveals that this scattering feature presents a slight asymmetry on its right side indicating that a certain amount of alloy remains in crystalline state. At this point, the alloy is composed by $\mathrm{Fe}(\mathrm{Si}, \mathrm{B})$ crystallites embedded in an amorphous matrix. According to the XRD pattern of the sample wet milled for 40 or 50 hours using oleic acid as PCA the alloy are however fully amorphous.

Analysing the XRD spectra of the powder wet milled using benzene as PCA it can be observed that after 5 hours of milling the same nanocrystalline $\mathrm{Fe}(\mathrm{Si}, \mathrm{B})$ solid solution is obtained. This solid solution is fully amorphised after 20 hours of milling. The XRD pattern of this sample presents a single and very broad maximum characteristic of the absence of long range atomic order specific for the amorphous materials. At this point of our investigation, we can conclude that the PCA plays an important role in the alloy amorphisation.

According to different investigations reported in the literature, one of the main drawbacks of the wet mechanical alloying is the contamination of the processed powders with atoms resulted from the decomposition of the PCA [3]. Considering that the PCAs used in this investigation contain a relatively large amount of carbon atoms, it is natural to assume that the powder is contaminated by a certain amounts of carbon atoms. The amount of carbon atoms contaminating the alloy depends upon the chemical composition of the PCA and can lead to a faster or slower amorphisation of the alloy.

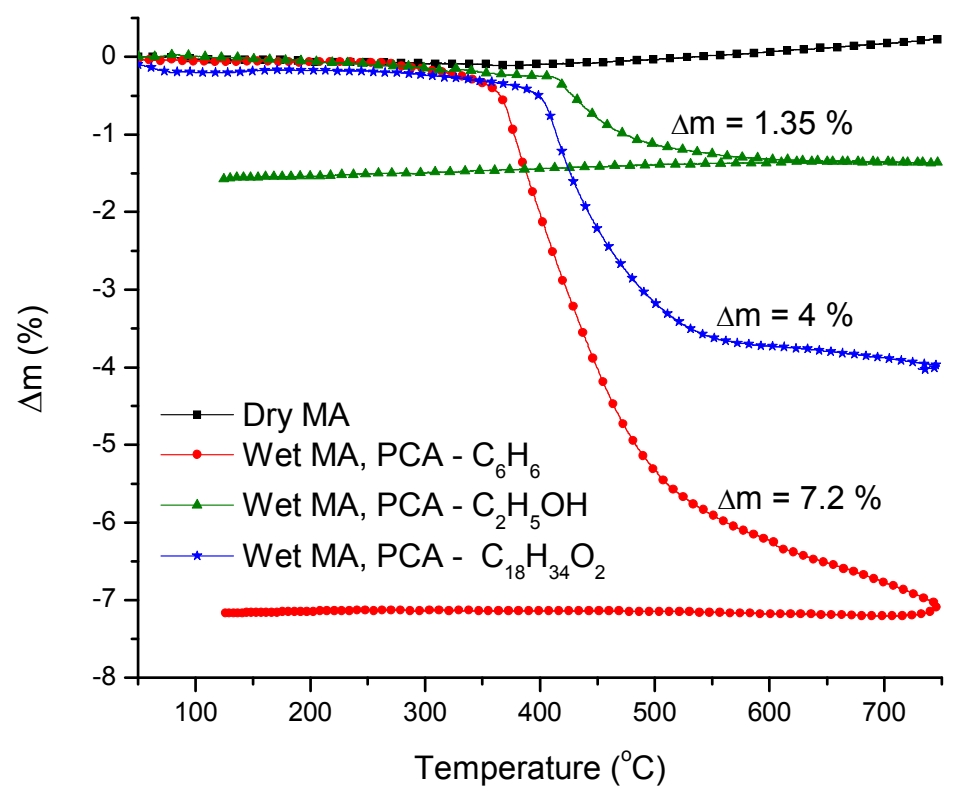

Fig. 2. Thermogravimetric curves in hydrogen atmosphere of the dry and wet mechanically alloyed powders for 50 hours. The maximum mass variation is indicated for all samples. 
In order to study the powder contamination with carbon atoms and to quantify this contamination, TG measurements in hydrogen atmosphere were performed. The TG curves of the samples dry and wet milled using ethanol, oleic acid and benzene as PCA are presented in figure 2 . It can be remarked that the TG curve of the dry milled sample is an almost straight line showing, as expected, no mass changes during heating up to $750{ }^{\circ} \mathrm{C}$ in hydrogen atmosphere. Considering the reducing nature of the used atmosphere, and the fact that dry milled sample present no mass variation during heating, it can be underlined that no significant oxidation of the dry milled powder occurred during milling up to 50 hours. In the TG curves of the wet milled samples, a decrease of their mass can be observed. It is worth to be noticed that the mass decrease of the powder wet milled with ethanol represents $1.35 \%$ of the sample mass while the mass variation of the sample milled using oleic acid and benzene as PCA represents $4 \%$ and $7.2 \%$ respectively of the sample mass. The mass variation is most probably given by the decarburizing effect of the hydrogen atmosphere.

Even if the stability of the benzene molecule (aromatic ring) is larger compared to that of ethanol or oleic acid (chain like), is seems that the number of carbon atoms contained by the molecule is the main factor affecting the powder contamination and thus its amorphisation. Even if all PCAs used in this investigation contain carbon atoms, it looks like there is a certain amount of contamination needed for powder amorphisation.

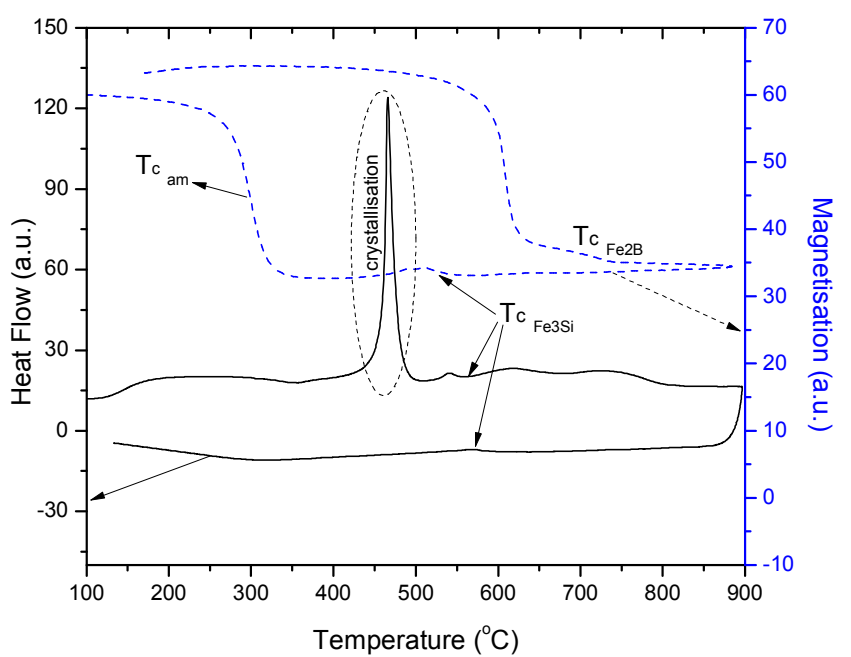

(a)

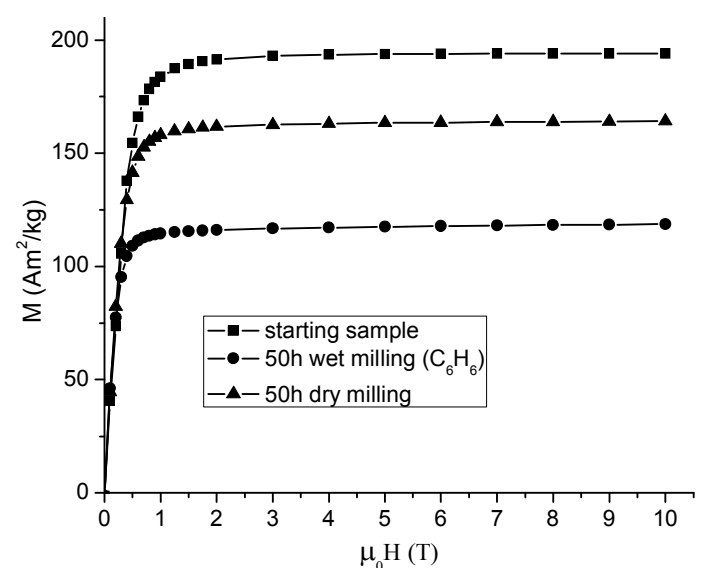

(b)

Fig. 3. DSC and $M(T)$ curves of the sample wet milled with benzene (a) heated up to the temperature of $900{ }^{\circ} \mathrm{C}$ and magnetisation curves at room temperatures up to $10 \mathrm{~T}$ for the samples dry and wet milled with benzene up to 50 hours (b). For comparison reasons the saturation magnetisation curve of the starting sample is presented.

In the DSC curve presented in figure 3a a broad exothermic peak can be observed in the 150 $350{ }^{\circ} \mathrm{C}$ temperature range. This peak was assigned to the stresses release, stresses induced during mechanical alloying process. At about $450{ }^{\circ} \mathrm{C}$ the crystallisation of the amorphous powder can be remarked as an intense and sharp exothermic reaction. The Curie temperature of the main phase formed during powder crystallisation is observed on heating and cooling curve at about $575{ }^{\circ} \mathrm{C}$. According to the literature this Curie temperature was assigned to the $\mathrm{Fe}_{3} \mathrm{Si}$ phase [4].

Analysing the $\mathrm{M}(\mathrm{T})$ curve of the sample presented in figure 3a, an important drop of the sample magnetisation can be observed at the temperature of $300{ }^{\circ} \mathrm{C}$. This variation of sample magnetisation was attributed to the Curie temperature of the amorphous phase [5]. The sample crystallisation phenomenon can be observed on the $\mathrm{M}(\mathrm{T})$ curve at about $450{ }^{\circ} \mathrm{C}$ as an increase of the sample magnetisation. The increase of the sample magnetisation is given by the fact that at this temperature the formed $\mathrm{Fe}_{3} \mathrm{Si}$ phase is in ferromagnetic state. On the cooling curve of the sample a change of the curve slope can be observed and attributed, according to the literature, to the Curie temperature of 
the $\mathrm{Fe}_{2} \mathrm{~B}$ phase [6]. This phase is probably formed during the crystallisation phenomena observed at the temperature of $450{ }^{\circ} \mathrm{C}$.

The saturation magnetisations of the dry and wet milled powder (Fig. 3b) are lower compared to the saturation magnetisation of the starting sample as a result of structural and compositional changes induced by mechanical alloying. The non-magnetic atoms of $\mathrm{Si}$ and $\mathrm{B}$ are dissolved in the Fe structure upon increasing milling time leading to a diminution of the overall saturation magnetisation of the sample. Also, the saturation magnetisation of the wet milled sample is lower as compared to the one of the dry milled sample. This can be explained by the powder contamination with carbon atoms (obviously non-magnetic) and by the presence of a thin layer of benzene adsorbed on the particle surface as reported elsewhere [7].

\section{Summary}

To summarise the results of our study, the following conclusions can be drawn: (i) amorphous powder of $\mathrm{Fe}_{75} \mathrm{Si}_{20} \mathrm{~B}_{5}$ (at.\%) alloy was obtained by wet milling using benzene and oleic acid as PCA after 20 and 40 hours of MA respectively; (ii) dry milling up to $50 \mathrm{~h}$ leads to the formation of a nanocrystalline $\alpha-\mathrm{Fe}(\mathrm{Si}, \mathrm{B})$ solid solution; (iii) in the case of wet milled samples, the powder contamination with carbon was evidenced and was related to the amount of carbon contained by the molecule of PCA; (iv) the saturation magnetisation of the dry and wet milled powder is influenced by the structural and compositional changes induced by mechanical alloying.

Acknowledgment - This work was supported by a grant of the Romanian National Authority for Scientific Research, CNCS - UEFISCDI, project number PN-II-RU-TE-2012-3-367.

\section{References}

[1] P. Duwez, Structure and properties of alloys rapidly quenched from the liquid state, Trans. Am. Soc. Metals, 60 (1967) 607-633.

[2] Suryanarayana, Mechanical alloying and milling. Prog Mater Sci. 46 (2001) 1-184.

[3] A. Nouri, C,.Wen, Surfactants in Mechanical Alloying/Milling: A Catch-22 Situation, Crit. Rev. Solid State Mater. Sci., 39 (2014) 81-108.

[4] B.V. Neamţu, T.F. Marinca, I. Chicinaş, O. Isnard, F. Popa, P. Păşcuţă, Preparation and soft magnetic properties of spark plasma sintered compacts based on Fe-Si-B glassy powder. J. Alloy Compd. 600 (2014) 1-7.

[5] E. Fechová, P. Kollár, J. Füzer, J. Kováč, P. Petrovič, V. Kavečanský, The influence of the long time milling on the structure and magnetic properties of the $\mathrm{Fe}-\mathrm{Cu}-\mathrm{Nb}-\mathrm{Si}-\mathrm{B}$ powder, Mater. Sci. Eng. B, 107 (2004) 155-160.

[6] J. Fornell, S. Gonzalez, E. Rossinyol, S. Surinach, M.D. Baro, D.V. Louzguine-Luzgin, J.H. Perepezko, J. Sort, A. Inoue, Enhanced mechanical properties due to structural changes induced by devitrification in Fe-Co-B-Si-Nb bulk metallic glass, Acta Mater., 58 (2010) 6256-6266.

[7] B.V. Neamţu, O. Isnard, I. Chicinaş, C. Vagner, N. Jumate, P. Plaindoux, Influence of benzene on the $\mathrm{Ni}_{3} \mathrm{Fe}$ nanocrystalline compound formation by wet mechanical alloying: An investigation combining DSC, X-ray diffraction, mass and IR spectrometries. Mater. Chem. Phys., 125 (2011), 364-369. 